\title{
Literature Circles in a Synchronous Virtual Classroom: Educational MOOs to Support Student Online Interaction
}

\author{
JENNIE BALES \\ Summerdale Primary School, \\ Tasmania 7252, Australia \\ jenbales@iprimus.com.au
}

\begin{abstract}
This paper explores the features of educational MOOs to create a stimulating, synchronous environment for upper primary (elementary) students working in the virtual world of Learning Communities MOO. It focuses on how the features of MOOs are used by students to support and enrich their literature circle discussions. The data presented indicates that these experiences encourage and support students' interests and understanding of text through social interaction and purposeful dialogue. The results of this research suggest that online literature circle discussions conducted in an Educational MOO can operate successfully and that the MOO environment supports student discussions.
\end{abstract}

\section{INTRODUCTION}

With increased use of communication technologies to enrich student learning there is a need to investigate programs that not only provide opportunities for synchronous communication but also enhance and enrich learning in a focused way. This paper explores the features of educational MOOs to create a stimulating, synchronous environment for upper primary (elementary) students (10-12 year olds). MOOs (Multi-Object Orientated domains) are virtual spaces that allow for real-time communication between participants, providing a 'same time, same place' experience. This investigation sought to discover in what ways the features of educational MOOs are used by students to support and enrich their online literature circle discussions.

Data from four literature circle discussions conducted by primary students in simultaneous sessions in LC_MOO (Learning Communities MOO, 2000) was analysed to identify how students have used the features of this specific online environment to support their discussions. Three questions are addressed:

- In what ways are the communication features used by participants?

- How are MOO features used to support interaction?

- What evidence is there to demonstrate that these features facilitate and support literature circle discussions?

The findings from the data are part of a preliminary investigation for a larger research project and will assist in identifying suitable methodologies and research techniques. 


\section{Motivation for the Study}

As a teacher librarian in a large primary school, I am actively involved in supporting teachers to incorporate innovative programs that use information and communication technologies (ICTs) to enhance and enrich student learning. The possibilities of engaging students in regular dialogue with peers in other parts of Australia was seen as an exciting and stimulating extension to their classroom literature circle discussions. Involvement in a MOObased literature circle trial with Charles Sturt University (Bales, J. 2000) led to a growing appreciation of the educational benefits that could be gained for students.

The positive response of students to working in this online environment, their regular commitment to read and reflect on texts, the collaboration between the teacher librarians and students, and the application of the literature circle model in a virtual setting, stimulated me to explore this educational program further to understand it more fully.

The LC_MOO literature circle program under investigation involves the work of two teacher librarians working in Tasmania and Victoria. We have seen our role as facilitators of innovative ICT programs that support, extend and enrich the learning opportunities offered within our schools. Teacher librarians are ideally situated to introduce proven literacy strategies to our teaching colleagues and to increase awareness of how such strategies can be adapted to harness ICT potentials in an educationally rewarding manner.

\section{Review of the Literature}

Literature circles are literary discussions that focus on participants making sense and developing understanding of a selected text through social interaction. Harvey Daniels (1994) considers the literature circle model as a means to encourage independent reading and cooperative learning in a stimulating, social activity. Daniels presents a range of roles that participants adopt to support their literary discussions. These roles encourage readers to interpret texts in different ways and, in combination, lead to a multiple interpretation of a text through the application of a range of cognitive learning styles. Daniels (1994, p. 13) explains his model thus:

Literature circles are small, temporary discussion groups who have chosen to read the same story, poem, article, or book. While reading each group-determined portion of the text (either in or outside class), each member prepares to take specific responsibilities in the upcoming discussion, and everyone comes to the group with notes needed to help perform that job. The circles have regular meetings, with discussion roles rotating each session. When they finish a book, the circle members plan a way to share highlights of their reading with the wider community; then they trade members with other finishing groups, select more reading, and move into a new cycle. Once readers can successfully conduct their own wide-ranging, selfsustaining discussions, formal discussion roles may be dropped.

A key strength of the literature circle model is the social interaction that occurs when participants share ideas and responses. Wilson and Simpson $(1994$, p. 9) acknowledge "... the value of talk in assisting students' understanding, thinking and learning" during literature circle discussions. Holmevik and Haynes $(2000$, p. 4) argue that MOOs are 'socially constructed spaces' consisting of 'virtual' communities involved in 'real' social interaction. Hay and Hanson $(1999$, p.28) describe the use of LC_MOO in relation to adults participating in literature circle discussions. One significant conclusion reached in their findings is that 
'the MOO environment can heighten the concept of a literary community.' The social interaction and the MOO environment as identified by these authors will be investigated to see how they are used by young learners to conduct productive literature circles.

Much of the literature on educational MOOs relates to the practical and technical development of MOOs and examples of their use, predominantly in higher education institutions. Haynes (1998:176) emphasises their potential in opening "up a wealth of new learning opportunities and new ways of relating to our colleagues and students." The pioneer work of Amy Bruckman (1997) with children using MacMOOse for imaginative social interactions suggests possibilities for the use of Educational MOOs with young students in a more structured educational context. However, literature on primary students using educational MOOs to support specific learning programs is scarce. However, the potentials have been recognised within a literature-based context (Dawson \& Fitzgerald, 1999), and it is expected that the findings will contribute to the field.

\section{Location and context of the study}

The setting of this study is a part of the virtual world of Learning Communities MOO (LC_MOO) hosted by Charles Sturt University. MOOs can be accessed through client software and a telnet connection, or increasingly, through the World Wide Web. A telnet connection takes players to an entirely text-based environment, whereas Web access allows for the construction of a multimedia environment that can incorporate graphics, audio, hyperlinks etc. as well as text. Participants in this study accessed LC_MOO through a telnet connection using Pueblo software (Chaco Communications, 2000).

In broad terms, educational MOOs are purpose built 'spaces' consisting of rooms and objects that participants (or players) can enter and interact with. Players can develop their own personae by setting their gender and description. All objects can be 'described' and 'looked' at so that participants can 'view' them and develop a mental picture built from the text based descriptions. Virtual classrooms can be constructed that incorporate 'traditional' teaching tools such as notice boards, video recorders and seating areas. There are various ways to move around a MOO, including teleporting to a specified room, joining a player and taking a designated exit. A range of communication commands allow players to speak to everyone in a room, address one person, and 'page' or speak privately to anyone in the MOO at that time. Players can also express emotions and actions through use of the emote command. This research focuses on these environmental and communication features in relation to how they support the literature circle discussions under investigation.

\section{METHODOLOGY}

This project aims to investigate what occurs with primary students in a MOO-based online classroom environment. It is the pilot for a larger research project that explores primary students working synchronously in LC_MOO. The analysis of the pilot will provide the basis for collection and analysis to be used in the larger study.

\section{$\underline{\text { Selection of research setting }}$}

This research focuses on the environment of LC_MOO. This educational MOO has restricted access granted by the administrators, offering a secure and safe working 
environment for students. LC_MOO has a number of areas that can be used by educators including a section called Kidspace, an area specifically built to provide younger students with an appropriate working environment (see Appendix A for visual map of Kidspace areas). This study is based in a reading area constructed to host book discussions. After logging into LC_MOO students move to the Kidspace area and gather in the Readers' Lounge where they greet each other.

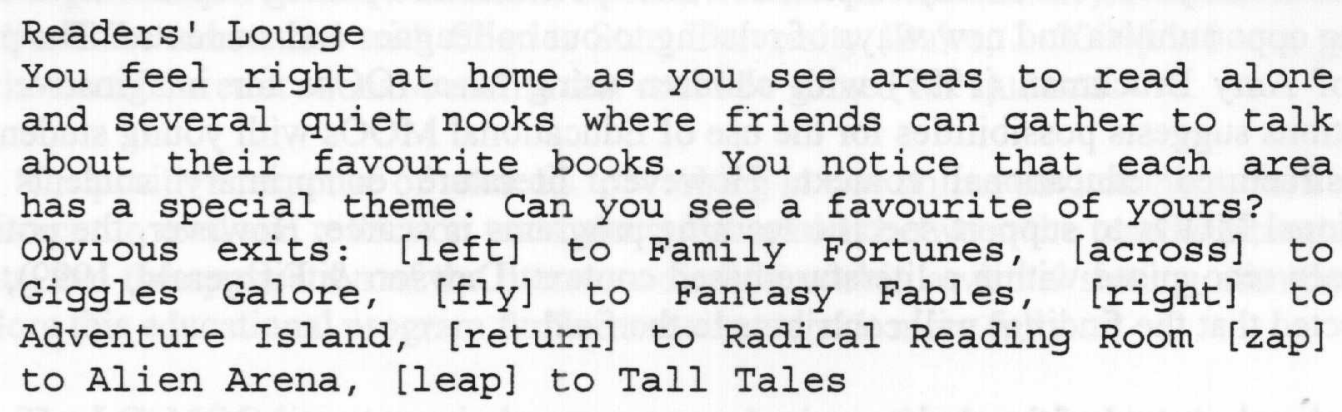

Students then move to their assigned rooms to conduct their literature circle discussions. Each room has its own description. For example, on typing the exit word 'left' students enter Family Fortunes...

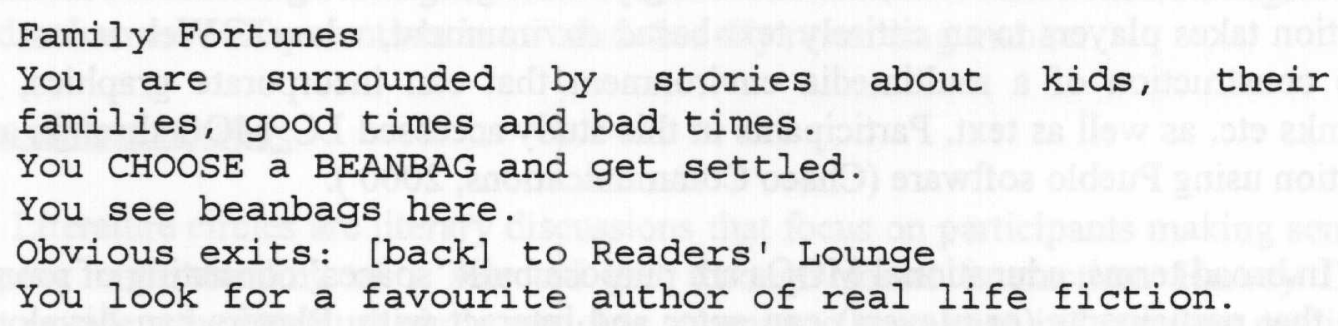

Objects such as the 'beanbags' encourage student interaction with the environment, in this case inviting the student to settle ready for a discussion.

\section{Collection of research data}

The researcher observed and participated in the online environment with the students. As a participant I was able to be a part of the group, working with the students as a teacher, guide, and at times, a discussion contributor, as well as an observer of the discussions taking place. This study used two methods of data collection: MOO transcripts and student evaluations.

A significant feature of MOOs is the ability to log sessions to provide transcripts of the dialogue occurring in each room. This feature captures all public dialogue and action as it occurs providing a complete record of events. Transcripts were saved simultaneously across each of the four rooms used in Kidspace by logging in extra 'players', identified as MOOCam1, MOOCam2 etc., and moving them into each room. Transcripts accurately record all input from the researcher so that any bias occurring as a result of interactions with the researcher can be identified and studied in relation to other activities.

Student evaluations were used to collect students' personal responses to their literary discussions in LC_MOO. These evaluations were designed to be a part of the students' classroom personal learning records and provide valuable insights into the students' feelings 
about LC_MOO as a place to conduct literature circles. This data provides participant perspectives that could not be captured in transcripts, offering alternative viewpoints to improve the validity of conclusions drawn.

\section{$\underline{\text { Study Participants }}$}

The participants for this study were drawn from two schools involved in the 'Literature Circle LC_MOO' program. It included the participating teacher librarians and students. The teacher librarian participants approached classroom teachers of Grade Five and Six students (aged 10 to 12 years) to select $8-10$ students to be involved. Students were identified by their teachers according to whom the teachers thought would benefit educationally from involvement in the program.

One group of students was drawn from an urban private girls' school, each with their own laptop computer and a strong background in the use of technology. The second school was an urban middle class public school, where the students had access to five computers in their classrooms and a two years experience with regular use of computers in their education. Students went to the school library to log on to LC_MOO either with their personal laptop or a school desktop computer. Once a formal decision to undertake research was made the necessary ethical issues were addressed by gaining permission from school principals and parents for student involvement and the collection and use of data.

This study analyses data collected mid way through the academic year when students had grasped the fundamentals of communicating in a MOO and had some experience in conducting online discussions. Four concurrent literature circles were logged in June 2000 where small groups of four or five students discussed their reading in four rooms of LC_MOO (Adventure Island, Family Fortunes, Fantasy Fables and Giggles Galore). The students were reading the short stories of Australian author Andy Griffiths. The stories to be discussed were selected by the student groups. These included 'Tell ya mum I saved ya!' and 'Born to die' from Just Tricking, and 'Murder Bloody Murder' and 'Are we there yet?' from Just Annoying. Student preparation for the online discussion involved reading the short story and preparing for their selected roles. Appendix B provides an explanation of some of the roles as they are presented on the role sheets used by students in this study.

\section{Analysis of the Data}

Analysis of transcripts was carried out using NVivo, a qualitative software program designed to facilitate the analysis of documents in a range of formats. The transcripts of each of the groups' discussions were analysed. Previous experience in manually coding transcripts helped identify preliminary groupings for the coding of data. Three main categories were identified to address the key ideas in the research questions:

- Communication Type

- Environment

- Literature Circle

Responses from the student evaluations were manually compiled and collated and entered in to spreadsheet software. The evaluations were examined to identify students' feelings, as well as identify any benefits students saw in conducting literature circles in LC_MOO. 


\section{Coding system for transcript analysis}

The coding system evolved by identifying key concepts in each of the research questions and developing a system to identify and track related data.

\section{In what ways are the communication features of educational MOOs used by} students?

Coding was applied to identify different types of communication and included the following sub-categories:

- Addressing (a specific person by name eg. Dani_LL [to Micheal]: How ...”)

- Long speech - ellipses (breaking up long passages of dialogue to assist reading)

- Sign (message presented in a box to make it stand out)

- Imaginary extension (participant response to the virtual setting and dialogue)

- Emoting (an emotional or physical response rather than spoken) subdivided into: Actions, Feelings, Humour and Thoughts

- Mistake (with commands etc.)

The standard form of communication that names the speaker and presents the dialogue to everyone in the room was not coded (eg. Michael_VE says, " I got ..."). The identification of 'non-dialogue' text in a transcript was necessary to calculate the proportion of 'Communication Types' in relation to participant dialogue. Coding under 'Environment' facilitated this function (see below for details)

\section{How are MOO features used to support interaction?}

Coding under 'Environment' was designed to allow for the identification and study of specific MOO features that assist participants in their interactions with others. These covered:

- Movement

- Object Interaction - Programmed

- Room Description

- Room - Programmed response

- Who (shows who is connected and where they are located)

3. What evidence is there to demonstrate that these features facilitate and support literature circle discussions?

The dialogue specifically relating to the students literature circle discussions was coded to distinguish between the different roles and to identify questions and responses. Dialogue or discussion ideas added by the person initiating that discussion point was coded 
as a response. Acronyms used by students to identify their online roles were also used in the coding structure. Role names included:

- DD - Discussion Director

- C - Connector

- ILL - Illustrator

- LL - Literary Luminary

- VE - Vocabulary Enricher

\section{FINDINGS}

This research aims to identify the ways in which features of LC_MOO were used by students and to see in what ways these supported their online literature circle discussions. Analysis of these four separate discussions provide valuable insights into how students operate in and use this virtual world to support their dialogue. The results of the analysis are addressed under the research questions.

\section{In what ways are the features of educational MOOs used by students?}

Figure 1 presents the statistical results of students' use of a range of communication types. These include the use of: communication commands (address, sign, emote), ellipses, imaginary extension and mistakes made in communicating.

Figure 1

\section{Communication Types}

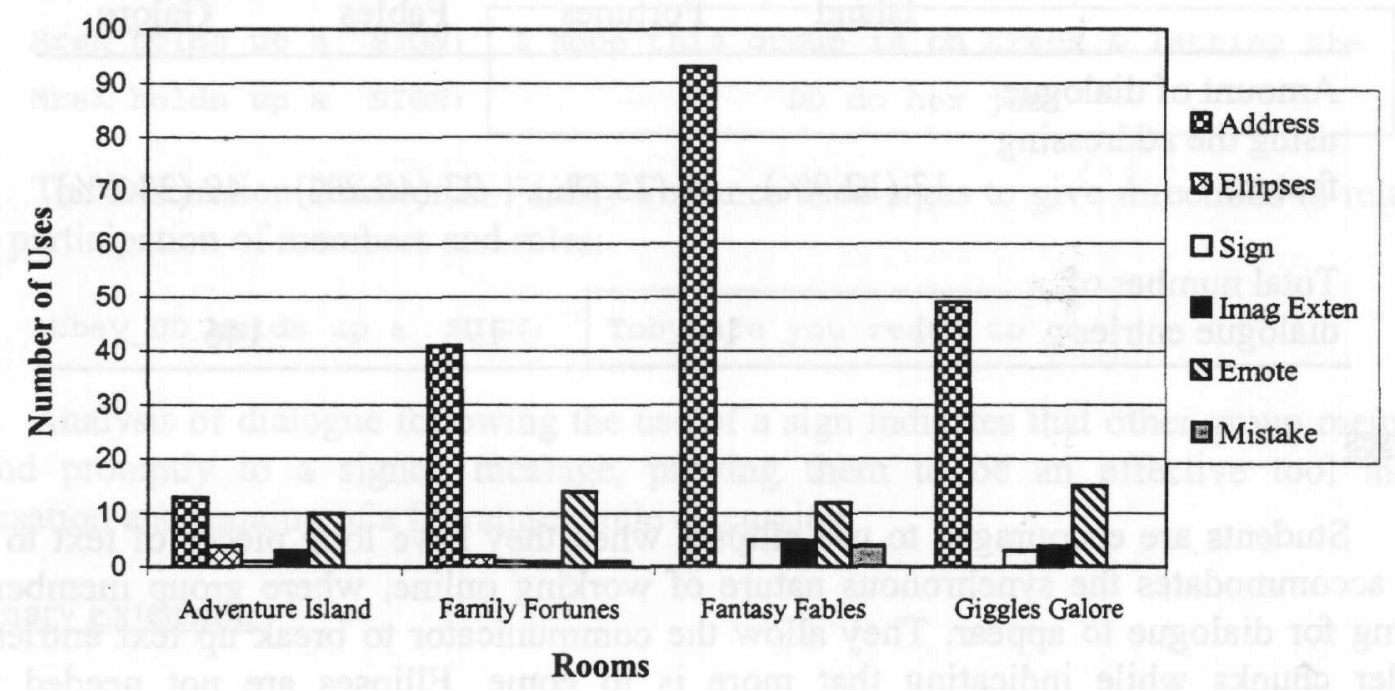

\section{$\underline{\text { Address }}$}

Addressing helps participants respond to the different threads of conversations that occur simultaneously within group discussions. Working synchronously means that text from one person can interrupt another's dialogue, and addressing helps to identify who is being spoken to. The use of this communication feature was much greater than any other and especially noticeable in Fantasy Fables. A study of an extract from Family Fortunes shows 
how this communication feature facilitates understanding. Grace is making a Literary Luminary comment and also following up a query of Emily's. The addressing feature makes the meaning of each statement clear to all.

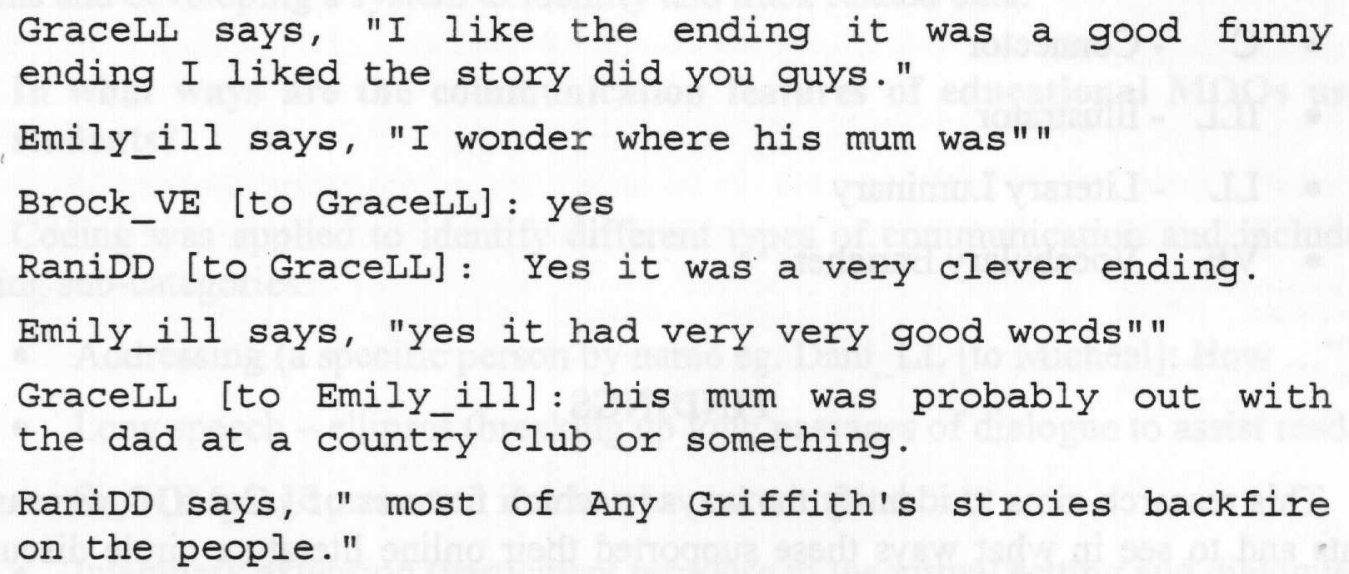

Statistically the results of the use of the addressing command shows a wide variation between rooms. This variation is better understood when the results are compared with the total number of dialogue interactions in each room as shown in Table 1. When these two factors are considered together it would appear that the more articulate groups use this command with considerable ease.

\section{Table 1}

Comparison of the use of the addressing command and the amount of dialogue in each room

\begin{tabular}{lllll}
\hline & $\begin{array}{c}\text { Adventure } \\
\text { Island }\end{array}$ & $\begin{array}{c}\text { Family } \\
\text { Fortunes }\end{array}$ & $\begin{array}{c}\text { Fantasy } \\
\text { Fables }\end{array}$ & $\begin{array}{l}\text { Giggles } \\
\text { Galore }\end{array}$ \\
\hline $\begin{array}{l}\text { Amount of dialogue } \\
\text { using the addressing } \\
\text { feature }\end{array}$ & $13(12.9 \%)$ & $41(25.5 \%)$ & $93(48.2 \%)$ & $49(33.6 \%)$ \\
$\begin{array}{l}\text { Total number of } \\
\text { dialogue entries }\end{array}$ & 101 & 161 & 193 & 146 \\
\hline
\end{tabular}

\section{$\underline{\text { Ellipses }}$}

Students are encouraged to use ellipses when they have long pieces of text to type. This accommodates the synchronous nature of working online, where group members are waiting for dialogue to appear. They allow the communicator to break up text entries into smaller chunks while indicating that more is to come. Ellipses are not needed when communication is short and responses are made quickly. Only two rooms used this aspect of communication and there were six examples altogether.

All four students in Adventure Island used ellipses to begin a question. For example:

Travis_DD says, "my first question is...."

Travis_DD says, "What do you think could have happend if Danny got the right bag?"

Inspiring connections: Learning, libraries \& literacy 
There were two uses of ellipses in Family Fortunes. In both cases they were used to initiate further discussion on a point of discussion. For example:

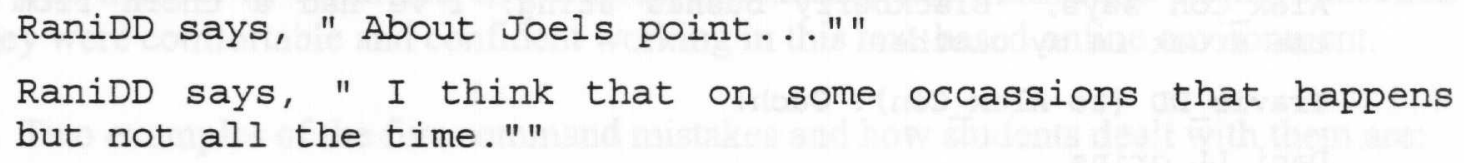

$\underline{\text { Sign }}$

The sign is a programmed communication feature that inserts text into a box that is indented into the dialogue. It is an effective tool for drawing everyone's attention to an issue or instruction. Overuse of signs can break up the flow of conversation on the screen and to avoid this their use is generally restricted to the Discussion Director role to facilitate group organization. The use of signs was expected to be minimal: what was of interest was the way in which they were used.

Signs were used in each room with the most examples in Fantasy Fables. Purposes for the signs vary. Some relate to the movement of people. In the following example Travis, the Discussion Director in Adventure Island, as has been paged (sent a private message that only appears on the recipient's screen) a direction from a teacher librarian participant to instruct his group to return to the Readers' Lounge:

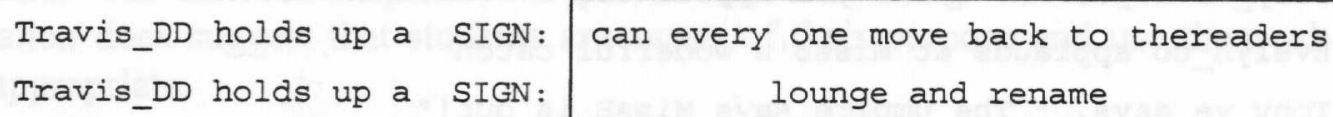

The next example shows how effective signs can be for teachers in $\mathrm{MOO}$ to give direction or instructions. MrsK (a teacher librarian participant) was supervising in Family Fortunes when she felt some intervention was necessary.

$\begin{array}{ll}\text { MrsK holds up a SIGN: } & \text { Mrsk holds up a SIGN: } \\ \text { Mrope this group is on track \& letting the } \\ \text { DD do her job. }\end{array}$

The Discussion Director in Family Fortunes used signs to give directions in relation to the participation of members and roles:

$$
\text { Abbey_DD holds up a SIGN: Toby are you ready to go }
$$

Analysis of dialogue following the use of a sign indicates that other group members respond promptly to a signed message, proving them to be an effective tool in the organisation and running of a literature circle discussion.

\section{Imaginary Extension}

Imaginary extension is an application of a communication feature, such as the emote command, that gives an indication of participants' acceptance of their presence in a virtual world as being 'real' to them. It may be in response to an object in the MOO environment, or to an interplay of dialogue with other participants. There were only a few examples of this type of communication, but its use adds a further dimension to the dialogue. 
In Adventure Island while discussing a connection made relating to falling into a prickle bush the following dialogue ensued.

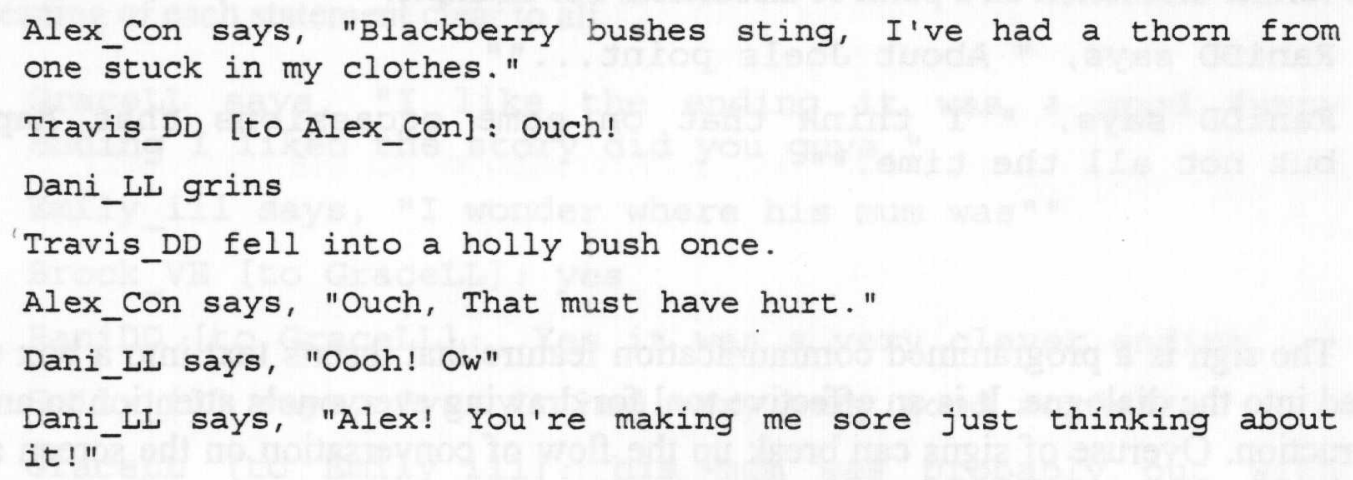

This gives a sense of the students 'feeling' each other's pain in real life.

In Fantasy Island a teacher librarian participant (MissB) initiated an emotive and descriptive response to the Vocabulary Enricher's discussion of the word 'Howzat!'

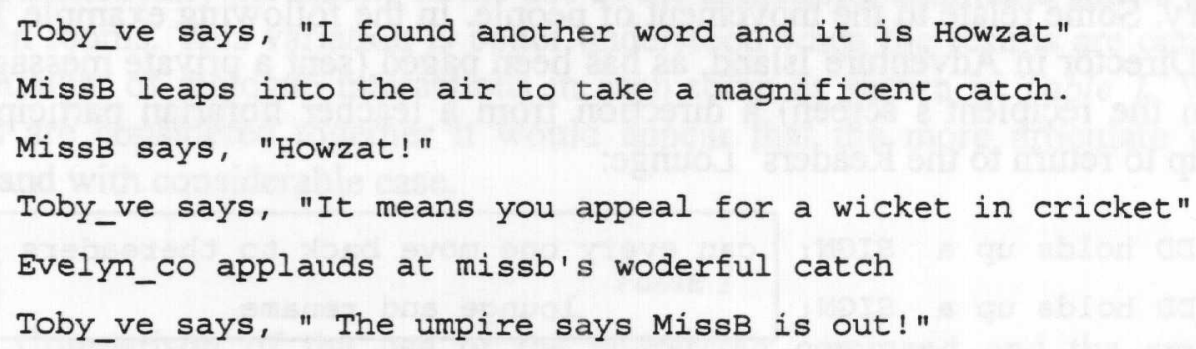

The rich interplay of dialogue when participants use their imaginations to make their text environment more 'real' suggests imaginary extension during a literature circle discussion gives an added dimension to the nature of the dialogue.

\section{Emoting}

Emoting was coded to identify the purposes of emotes that showed either action, humour, feelings or thoughts. In total, emotes consisted of an average of $7 \%$ of all dialogue. Emotes can add a further dimension to the dialogue by providing group members with a 'visual' clue to how participants are feeling or what they are doing. In a sense it is an alternative to non-verbal communication that they would be sharing in a face-to-face literature circle discussion.

Action: FrancisDD looks around to see who else is here.

Humour: Dani_LL giggles.

Feelings: Dani_LL is embaressed. She didn't realise it said "i'm in a pricle bush.

Thoughts: Alex_Con agrees with MissB.

There were insufficient examples of emoting to draw conclusions about its significance. However the examples observed in these transcripts suggest it is a communication feature that has potential to enhance discussions. 
$\underline{\text { Mistake }}$

The number of command errors made by students was minimal, a strong indication that they were comfortable and confident working in this text-based online environment.

Two examples of the five command mistakes and how students dealt with them are:

(i) In using the addressing command

$$
\begin{aligned}
& \text { Evelyn_co [to ]: emma } \\
& \text { [two lines later, self corrected] } \\
& \text { Evelyn_co [to Emma_LL] : same }
\end{aligned}
$$

(ii) In interacting with an object:

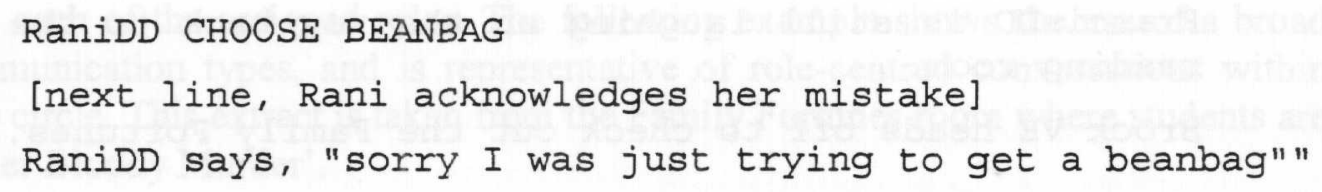

Results of content analysis (see Figure 1) of the types of communication used by students showed that use of specific features for communication, beyond the standard speech command, was not wide spread except for the addressing command. However, their application does suggest that students are aware of their purpose and use them when they seem appropriate.

\section{How are MOO features used to support interaction?}

Certain programmed features of LC_MOO help keep participants informed of where people are located, when people arrive or leave a room and if they are actively participating. These assist participant functionality in the MOO environment and are valuable classroom management tools for teachers working with students.

\section{$\underline{\text { Room Description }}$}

When a person enters a room the room description automatically comes up. It is followed by a list of players already in the room. (highlighted here for clarity)

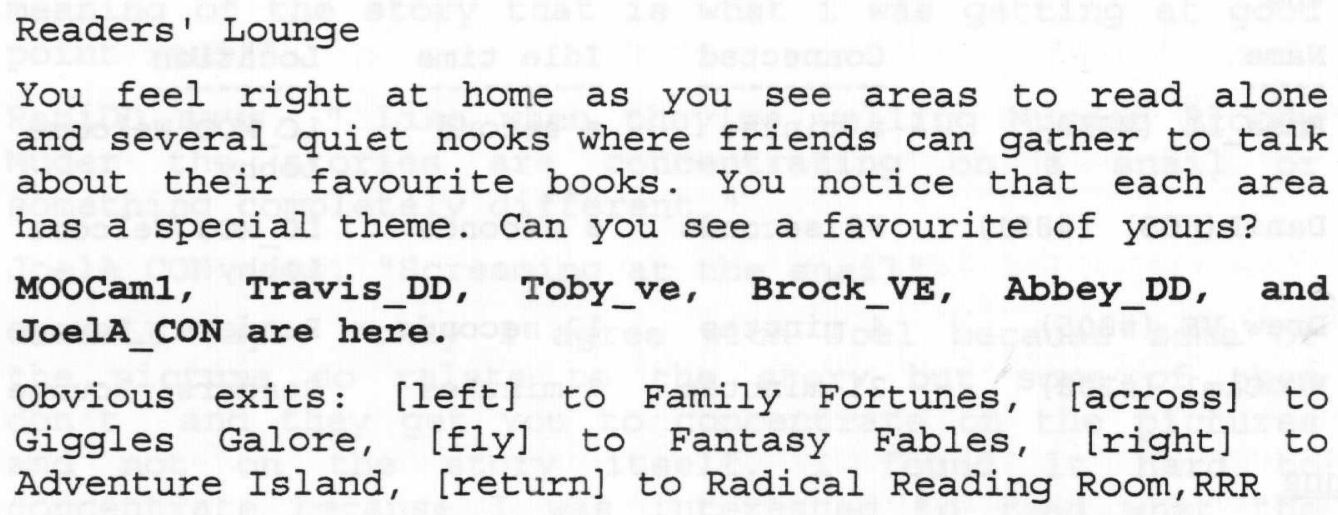


Typing a 'look' command will refresh the room's description if a person needs to check who is still in the same room. This feature supports student interactions by providing confirmation of who is present in a room when participating in discussions.

\section{Movement}

In-built programming informs a player when someone leaves or enters a room:

Mrsk arrives.

Mrsk leaves.

This can be personalised so that specific messages appear during movement. These messages are designed to keep participants aware of who they are working with and where they are going to:

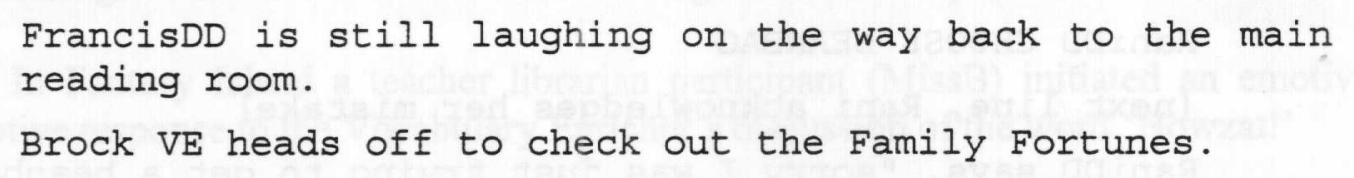

A person disconnecting is also broadcast. There are numerous examples of students responding to these messages and being aware of movement and activity:

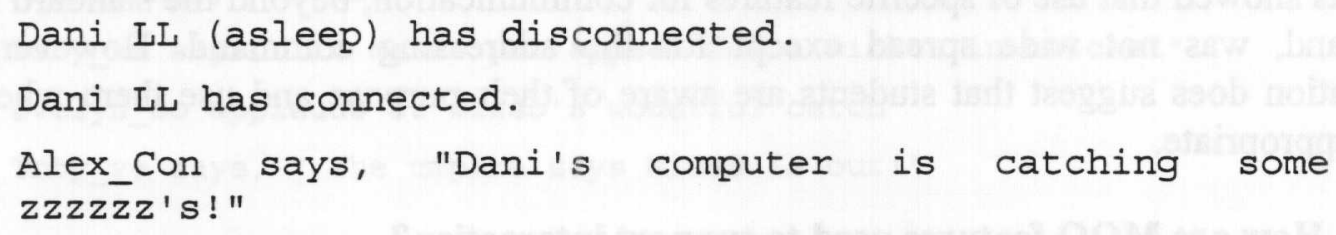

These movement messages are important for helping those in a room be aware of what is happening to individuals, and when others come and go, so that participants know who is sharing the same virtual space or 'room'.

\section{Location and Activity}

This edited example of the 'who' function shows the location of some of the players, how long they have been connected and the time they have been idle (not communicated or moved). It is valuable for group management.

who

\begin{tabular}{|c|c|c|c|}
\hline Name & Connected & Idle time & Location \\
\hline Emma_LL (\#850 & a minute & a second & $\begin{array}{l}\text { LC_MOO Welcome } \\
\text { Lob̄by }\end{array}$ \\
\hline $\operatorname{DaniP}(\mathrm{KGS}) \quad(\# 851)$ & 59 seconds & 8 seconds & $\begin{array}{l}\text { LC_MOO Welcome } \\
\text { Lobby }\end{array}$ \\
\hline Drew_vE (\#805) & 4 minutes & 12 seconds & Readers' Lounge \\
\hline MooCam1 (\#208) & 21 minutes & 7 minutes & Readers' Lounge \\
\hline
\end{tabular}

$\underline{\text { Renaming }}$

The renaming function allows participants to change their names while logged in to LC_MOO. This has been an important tool in managing literature circles as students can 
identify their roles in their name structure. This is evident in earlier examples of dialogule where roles are indicated by appendages to student names. In the previous example it can be seen that Emma is a Literary Luminary, Drew is a Vocabulary Enricher and Dani has still to rename.

\section{What evidence is there to demonstrate that these features facilitate and support literature circle discussions?}

The transcripts were analysed to identify student use of LC_MOO features in thie discussions. Student evaluations were examined to identify their feelings about conducting literature circles in LC_MOO.

Transcript coding was used to identify passages of dialogue relating to the questionis and responses of specific literature circle roles. These were found in the transcripts of each room, and for each of the assigned roles. The following example shows the use of a broad range of communication types, and is representative of role-centred conversations within each literature circle. This extract is taken from the Family Fortunes room where students are discuss 'Murder Bloody Murder'.

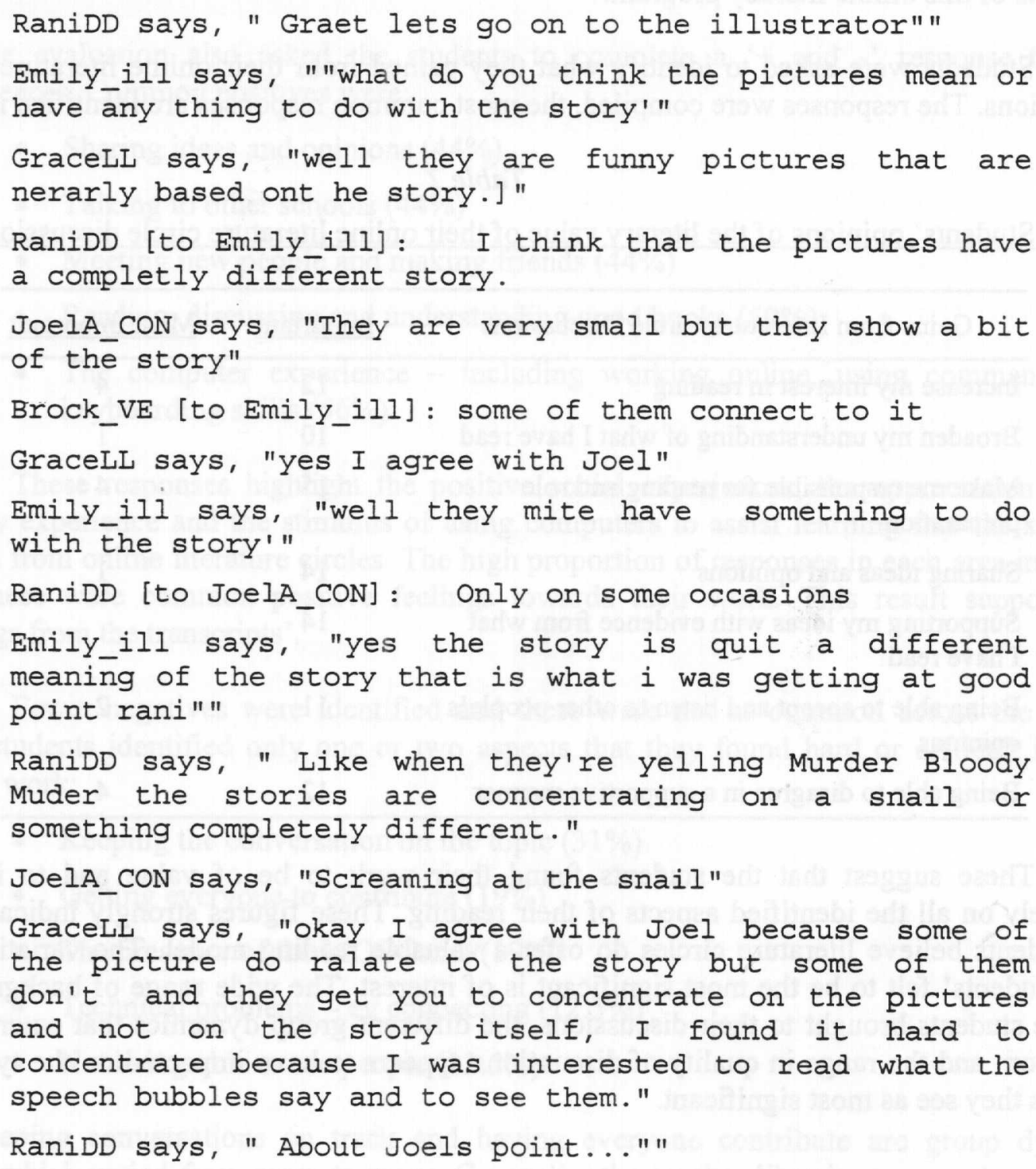




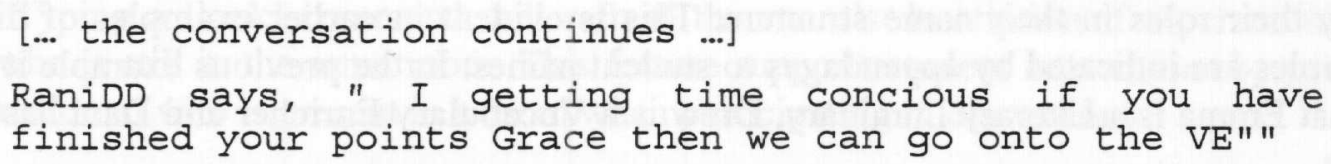

This extract indicates that features of a MOO environment can successfully support literature circle discussions. The naming of participants identifies each of their roles. There is a diverse use of communication commands and Rani, as Discussion Director, is taking a leadership role to keep the discussion moving. The addressing command is used by students to link their responses to specific comments or questions made by others. Ellipses are used appropriately. The result of this combined use of a range of communication features is a unified and connected piece of dialogue. The depth of the discussion, the willingness of the students to share and accept different points of view, and their ability to support their arguments, result in a meaningful literary discussion.

Student evaluations of LC_MOO literature circles were completed as part of their personal learning records. Although these evaluations were not designed as questionnaires to facilitate data collection, the responses of sixteen students provide interesting insights into the value of this online literacy program.

Students were asked to identify what they gained from their online literature circle discussions. The responses were compiled, the most common responses are identified in

\section{Table 2}

Students' opinions of the literary value of their online literature circle discussions

\begin{tabular}{lccc}
\hline \multicolumn{1}{c}{ Gains from Literature Circle Discussions } & Important & Most Important \\
\hline Increase my interest in reading & 12 & 4 \\
Broaden my understanding of what I have read & 10 & 1 \\
$\begin{array}{l}\text { Make me responsible for reading and role } \\
\text { preparation }\end{array}$ & 15 & 4 \\
$\begin{array}{l}\text { Sharing ideas and opinions } \\
\begin{array}{l}\text { Supporting my ideas with evidence from what } \\
\text { I have read }\end{array}\end{array}$ & 14 & 1 \\
$\begin{array}{l}\text { Being able to accept and listen to other people's } \\
\text { opinions }\end{array}$ & 11 & \\
Being able to disagree in a supportive manner & 12 & 2 \\
\hline
\end{tabular}

These suggest that the students found their work to be of value and to impact positively on all the identified aspects of their reading. These figures strongly indicate that the students believe literature circles do offer a valuable reading model. The variations in what students' felt to be the most significant is of interest. The wide range of backgrounds that the students brought to their discussions, the different group dynamics that emerged in each room and the range in quality of discussions appears to have impacted on the types of benefits they see as most significant. 
Students were also asked how they felt about the teacher librarian participants' involvement in the discussions. This was an issue of concern, as we had wondered to what extent we should become involved in the discussions. We felt that the MOO environment invited us to interact more spontaneously with the students as equals as well as in our teacher roles. We had found that the need for organisational input was usually minimal and that the students invited responses from us as literature circle participants. This is illustrated in the following query in the Adventure Island group:

Dani_LL [to MissB.]: Are you going to answer or are you just listening?

Fourteen of the sixteen responses were positive towards our participation with such affective comments 'better', 'relaxed', 'confident', 'good'. Reasons ranged from our presence keeping every one on track, to improving the discussion, encouraging and supporting individuals and that we challenged their thinking. The two negative responses stated that these students felt 'nervous' (in case they made a mistake) and 'embarrassed' (for the group if the discussion wasn't going well). The overall positive response to the teacher librarians actively participating in student discussions does suggest that this MOO environment supports social interaction between all participants.

The evaluation also asked the students to complete a '+ and -' response to their experiences. Common positives were:

- Sharing ideas and opinions $(44 \%)$

- Talking to other schools (44\%)

- Meeting new people and making friends (44\%)

- Reading, discussing and understanding good books (50\%)

- The computer experience - including working online, using commands and keyboarding skills $(56 \%)$

These responses highlight the positive social experiences, the appreciation of the literary experience and the stimulus of using computers to assist learning that the students gained from online literature circles. The high proportion of responses in each area indicates that these were common positive feelings towards their work. This result supports the findings from the transcripts'.

Fewer negatives were identified and these were not as common across the group; most students identified only one or two aspects that they found hard or difficult in their online work:

- Keeping the conversation on the topic (31\%)

- Getting everyone to contribute (19\%)

- The presence of the MOOCams (19\%)

- Technical problems - eg connecting (12.5\%)

- Not being able to see people $(12.5 \%)$

Keeping conversations on track and having everyone contribute are group dynamic issues which varied from room to room. Generally, the teacher librarians were pleased with 
how well students stayed on task during discussions, although there were instances when this did not happen. Contributions from individuals has not been analysed in this study, but personal observations indicate that some students (possibly four) had difficulty in responding to some questions, or their slower typing skills inhibited their ability to contribute in time with the flow of conversation. The identification of the MOOCams as a problem raised issues as these are a fundamental part of the data collection. Most students ignored them completely or saw their purpose merely as a recording instrument. The three who identified them as a negative added that they felt that if they did anything wrong, or 'mucked around' the teacher librarians would know about it and that it was like being watched. From the teacher librarians' perspectives, the MOOCams did offer us an inside look at the working relationships between students and level of discussions and we did use the resulting transcripts in positive ways as teaching tools to highlight examples of good questions and dialogue in their discussions.

\section{CONCLUSIONS}

Although this paper explores only one session of literature circles, the use of four separate discussions has helped to identify areas of commonality and difference between the groups on which to base conclusions. A range of MOO features have been identified and evidence shows that students can use these successfully in their interactions. Reasons for the variation in the amount of use of specific features have been suggested but not verified in this investigation. Although a noticeable variation in use of features between rooms has been identified, there is sufficient evidence to suggest that they are an important part of the dialogue and that these features do support student online interaction and discussion.

The study clearly shows how a MOO's inbuilt programmed features support student interaction. This has helped develop a clearer picture of ways that LC_MOO can support students in their literary discussions. With a constantly evolving environment and the development of rooms to represent specific texts, there is an indication that this aspect of LC_MOO warrants further investigation. Students' opinions support the views of the teacher librarian participants and the research findings that the use of MOOs can offer opportunities for valuable learning experiences. This study has shown that these experiences encourage and support students' interests and understanding of text through social interaction and purposeful dialogue.

The results of this research suggest that online literature circle discussions conducted within an MOO environment can operate successfully and that MOO features can facilitate student discussions. Limitations of this pilot study have been identified and will be addressed in a longitudinal study that investigates literature circle discussions in a LC_MOO in greater depth.

\section{REFERENCES}

Bales, J. (2000). Author visits in synchronous virtual environments: Real possibilities. Paper presented at 'New Millennium, New Horizons', Information Services in Schools (ISIS2000) Online Conference. Centre for Studies in Teacher Librarianship, Charles Sturt University, Wagga Wagga, NSW, 21-31 July. [Online] http://www.csu.edu.au/cstl/isis/participants/ papers/SF-Bales.html. 
Bruckman, A. (1997). MOOSE Crossing: Construction, community, and learning in networked virtual world for kids. PhD dissertation, Massachusetts Institute of Technology. [Online] http://www.cc.gatech.edu/ asb/thesis/ [accessed 02/01/01].

Chaco Communications (2000). Pueblo (MOO client). [Online\} at http://www.chaco.com [accessed 06/04/01].

Daniels, H. (1994). Literature circles: Voice and choice in the student-centred classroom. York, ME: Stenhouse.

Dawson, D. \& Fitzgerald, L. (1999). Literature circles: reading in action. Wagga Wagga, NSW: Centre for Information Studies, Charles Sturt University.

Griffiths, A. (1998). Just annoying. Sydney: Pan Macmillan.

Griffiths, A. (1997). Just tricking. Sydney: Pan Macmillan.

Hay, L. \& Hanson, K. (1999). Rethinking literature circles: reading and role-making in a virtual classroom environment. Orana. 35 (3), pp. 17-31.

Haynes, C. (1998). Help! There's a MOO in this class. In C. Haynes \& J. R. Holmevik (Eds.), High Wired: on the design, use, and theory of educational MOOs. University of Michegan Press.

Holmevik, J. R. \& Haynes C. (2000). MOOinversity: a student's guide to online learning environments. Boston: Allyn and Bacon.

Learning Communities MOO. (2000). Version 1.3, 10 March 2000. Supported by the Centre for Studies in Teacher Librarianship (CSTL) and Farrer Centre, Charles Sturt University, Wagga Wagga, NSW, Australia. (Online). [telnet: ispg.riv.csu.edu.au:8762].

Wilson, P. \& Simpson, A. (1994). Literature Circles: Children reading, writing and talking about literature. Literature Base, 5 (2), pp. 9-12. 
APPENDIX A

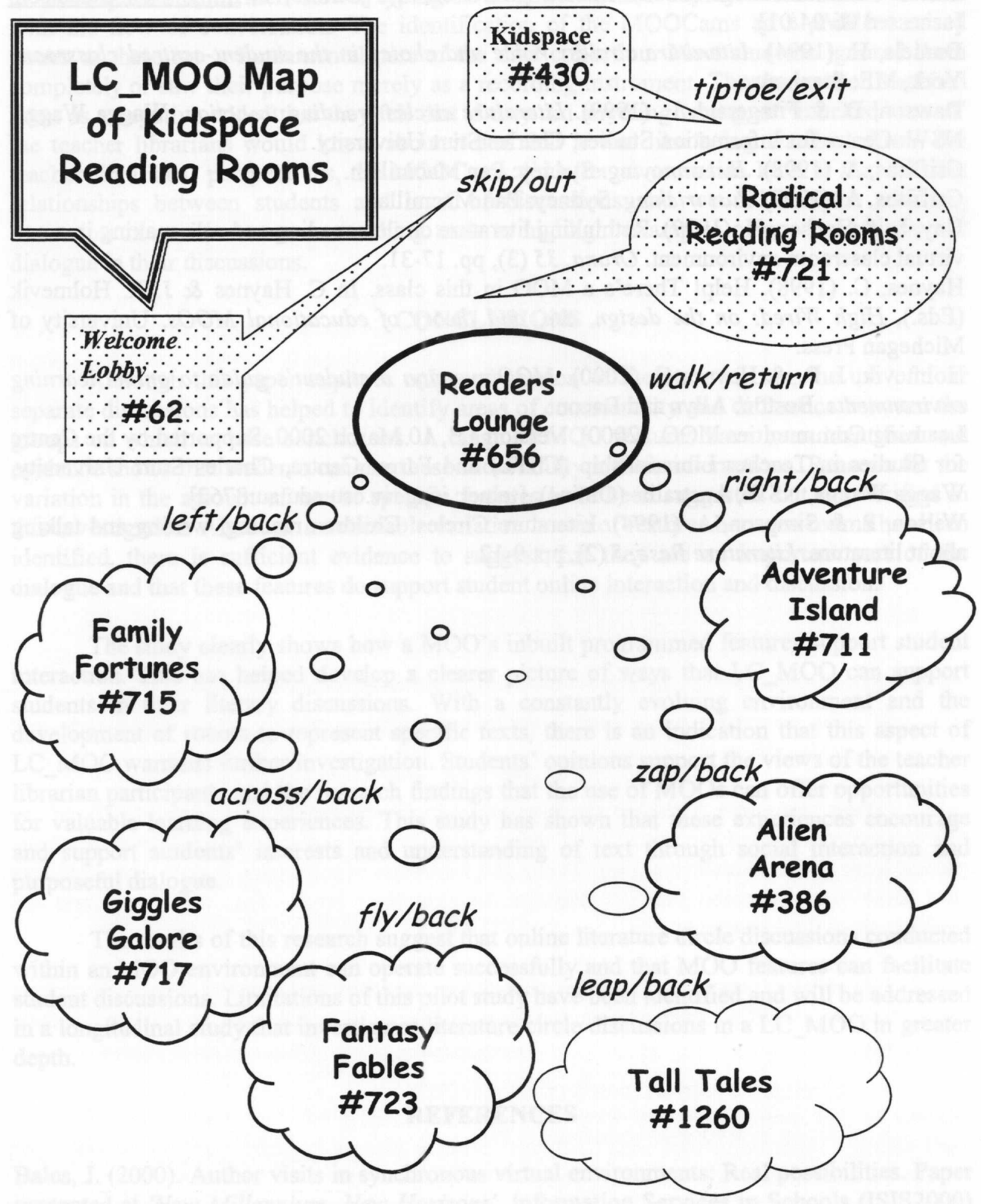




\section{APPENDIX B}

Examples of the role sheets used by students in this study. Adapted from Harvey Daniels (1994) to suit MOO-based literature circles.

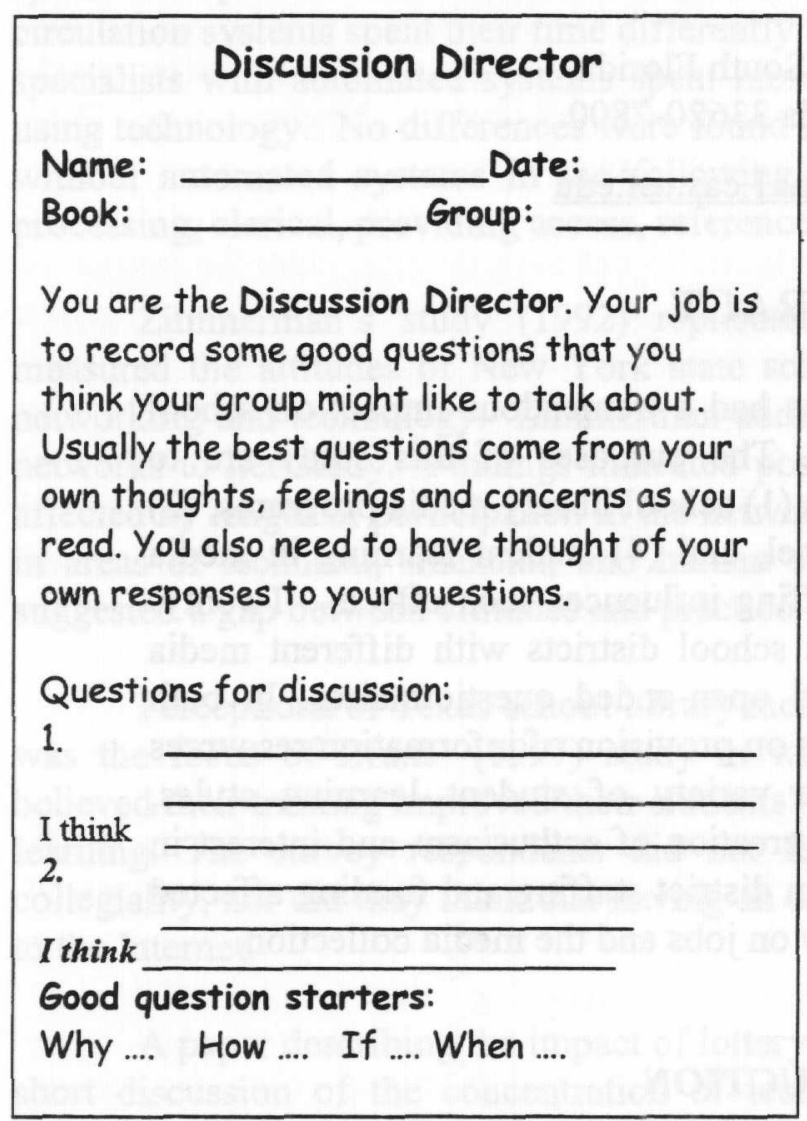

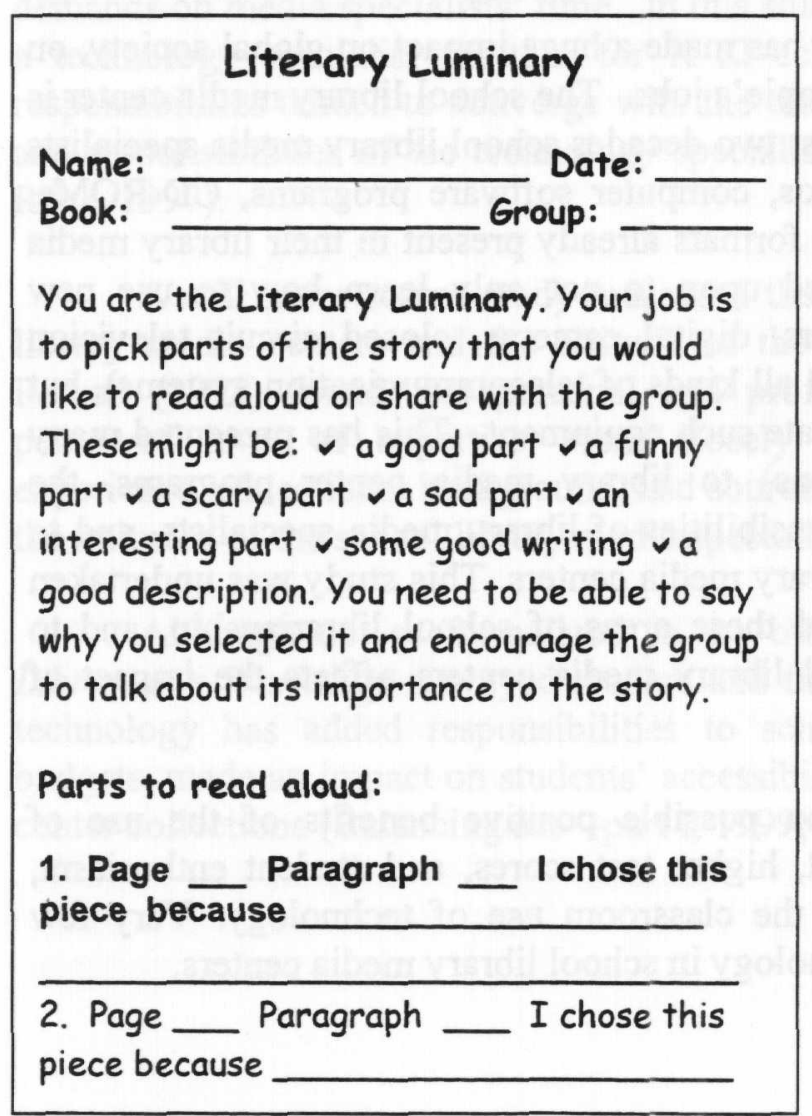

Inspiring connections: Learning, libraries \& literacy

\section{Connector}

Name:

Date:

Book: Group:

You are the Connector. Your job is to find connections between the book and the world outside. This means connecting the reading to: \& your own life s happenings at school or in the neighbourhood 8 similar events at other times and places \& other people or problems $\&$ other books or stories on the same topics 8 other writings by the same author.

Some connections I found between this reading and other people, places, events, authors...

1.

2.

3.

\section{Illustrator - Picture Books}

Name:

Book:

Date:

You are the Illustrator. Your job is to encourage your group to reflect on the illustrations. You could consider the medium used and the use of colour and space, how they add to the story, focus on a particular illustration and how it makes people feel.

Ideas for discussion:

1.

2.

3.

\section{Good question starters:}

Why do you think.... How do you feel.... In what ways ..... 